\title{
Inventori Fonem Vokal Dialek Melanau Rajang (Belawai) (An Inventory of Vowel Phonemes of the Melanau Rajang dialect)
}

\author{
MARINA KAWI* \& DAYANG SARIAH BT. ABANG SUHAI \\ Fakulti Bahasa Dan Komunikasi, Universiti Malaysia Sarawak, 94300 Kota Samarahan, Sarawak, Malaysia \\ *Corresponding author: marinakawi@gmail.com
}

\begin{abstract}
ABSTRAK
Kajian ini dijalankan untuk mengkaji inventori fonem vokal yang wujud dalam dialek Melanau Rajang di kawasan Belawai di bawah pentadbiran Daerah Tanjung Manis, Sarawak. Kajian ini merupakan kajian lapangan dengan menggunakan kaedah temu bual untuk mendapatkan data. Sebanyak 250 senarai daftar kata Swadesh (Samarin, 1967) digunakan sebagai panduan pengumpulan data. Dalam kajian ini, dua orang informan berlainan jantina yang berumur dalam lingkungan 40 dan 60 tahun telah dipilih berdasarkan kriteria-kriteria pemilihan informan menurut Asmah Haji Omar (2001). Dalam menganalisis data, kaedah kualitatif telah digunakan berlandaskan kepada pendekatan struktural. Hasil kajian membuktikan bahawa terdapat sebanyak lapan (8) jenis fonem vokal yang wujud dalam dialek Melanau Rajang di kawasan Belawai iaitu empat (4) vokal depan [i, e, $\varepsilon$, a], satu (1) vokal tengah [ə] dan tiga (3) vokal belakang [u, o, o]. Selain itu, distribusi/alternasi bagi kesemua fonem vokal dalam dialek Melanau Rajang di kawasan Belawai turut dibincangkan dalam kajian ini. Dapatan turut menunjukkan bahawa fonem vokal yang aktif ialah fonem vokal [a, i, u], manakala fonem vokal yang tidak aktif ialah vokal $[0, \mathrm{o}, \varepsilon$, , , e].
\end{abstract}

Kata kunci: Alternasi, Fonem, Fonologi, Melanau Rajang, Struktural

\begin{abstract}
The study aims to identify an inventory of vowel phonemes of Melanau Rajang dialect in Belawai under the administration of Tanjung Manis District, Sarawak. This study is a field survey using interview methods to obtain data. A total 250 Swadesh list (Samarin, 1967) are used as a guide for data collection. In this study, two infotmants of different genders aged between 40 and 60 years old were selected based on criteria of informant selections according to Asmah Haji Omar (2001). In analysis data, qualitative method is used based on structural approaches. The findings show that there are eight (8) vowel phonemes have been identified; four (4) front vowels [i, e, $\varepsilon, a]$; one (1) central vowel [o]; and three (3) back vowels [u, o, o]. Besides that, the distribution/alternation of all vowel phonemes of Melanau Rajang dialect in Belawai are also discussed in this study. The findings also indicate that active vowel phonemes are vowels $[a, i, u]$, while inactive vocal phonemes are vowels $[\supset, o, \varepsilon, \supset, e]$.
\end{abstract}

Keyword: Alternation, Melanau Rajang, Phoneme, Phonology, Structural

Copyright: This is an open access article distributed under the terms of the CC-BY-NC-SA (Creative Commons-NonCommercial-ShareAlike 4.0 International License) which permits unrestricted use, distribution, and reproduction in any medium, for non-commercial purposes, provided the original work of the author(s) is properly cited.

\section{PENGENALAN}

Bahasa menurunkan pelbagai dialek yang berbeza dari aspek tatabahasa dan kosa kata disebabkan faktor geografi kawasan pertuturan dialek (Noor Azureen Hamid et al., 2016). Terdapat banyak bahasa di Malaysia yang dapat dipecahkan kepada beberapa dialek di setiap kawasan lebih-lebih lagi di Negeri Sarawak kerana Malaysia termasuklah Sarawak memiliki masyarakat dan bahasa yang pelbagai. Menurut Pei (1960), sesuatu dialek mempunyai bentuk-bentuk yang tertentu dituturkan dalam kawasan tertentu, berbeza daripada bentuk yang standard dari segi sebutan, tatabahasa dan penggunaan kata-kata tertentu, tetapi perbezaan itu tidaklah begitu besar untuk dianggap sebagai satu bahasa yang lain (dipetik dalam Salbia Hassan, 2016).

Masyarakat Melanau merupakan salah sebuah kaum yang terdapat di Sarawak yang mempunyai ramai bilangan penduduknya dan turut mempunyai pelbagai dialek yang dituturkan. Menurut statistik Banci Penduduk dan Perumahan Malaysia 2010 yang dikeluarkan oleh Jabatan Perangkaan Malaysia, Melanau merupakan suku kaum 
kelima terbesar di Sarawak dengan peratusan lima peratus iaitu sebanyak 123,410 orang daripada keseluruhan 2,471,140 orang (dipetik dalam Tengku Intan Zarina Tengku Puji et al., 2014).

Berdasarkan Yasir Abd Rahman (1987:5), terdapat empat kelompok utama dalam pola penempatan Melanau di Sarawak iaitu kawasan Rajang (Belawai, Rajang, Paloh, Daro dan Matu), kawasan Mukah-Dalat (Mukah, Jebungan, Penakub, Teh, Sesok, Tetus, Tellian, Petanak, Oya, Igan, Dalat, Kut, Medong dan Narub), kawasan Balingian-Tatau (Sungai Balingian dan Sungai Tatau) dan kawasan Bintulu (Sungai Kemena dan Sebiew). Kebanyakan kajian berkaitan dengan dialek Melanau dijalankan di kawasan tertentu yang menjadi tumpuan seperti Melanau Mukah, Oya, Dalat dan Matu-Daro terutamanya dalam bidang fonologi.

Kajian fonologi bagi bahasa Melanau yang pernah dijalankan seperti kajian Norfazila Ab. Hamid (2016) hanya mengkaji fonem vokal dan diftong dalam Bahasa Melanau Oya. Kajian Norfazila Ab.Hamid dan Rahim Aman (2016) telah membuat penambahan dalam kajian fonologi Melanau iaitu dengan mengkaji fonem vokal, konsonan dan diftong yang difokuskan kepada dialek Melanau Mukah sahaja. Masih terdapat banyak lagi kawasan Melanau yang belum diterokai kajian bahasanya. Antaranya ialah di kawasan Melanau Rajang termasuklah Belawai yang masih belum diterokai terutamanya berkaitan dengan fonologi kawasan tersebut. Tambahan pula, dialek Melanau Rajang mempunyai variasi yang berbeza dengan dialek Melanau yang lain.

Dalam makalah ini, matlamat kajian adalah berfokuskan kepada inventori fonem vokal dalam dialek Melanau Rajang di kawasan Belawai. Selain itu, kajian ini bermatlamat untuk meneliti distribusi bagi fonem vokal yang wujud dalam dialek Melanau Rajang di kawasan Belawai tersebut sama ada berada pada kedudukan awal, tengah ataupun akhir kata. Kajian ini dijalankan untuk melihat dan meneliti fonem vokal yang wujud dalam dialek Melanau Rajang di kawasan Belawai sahaja dan mengenal pasti sama ada fonem vokal yang wujud dalam dialek tersebut menjalankan beban tugas yang penuh ataupun sebaliknya.

\section{METODOLOGI KAJIAN}

Kajian ini berlandaskan kepada beberapa metodologi yang digunakan untuk memperoleh data seperti menggunakan pendekatan struktural yang dipelopori oleh Ferdinand de Saussure (1960). Kaedah kualitatif yang bersifat deskriptif sangat sesuai digunakan dalam pendekatan struktural bagi memerihalkan aspek bunyi-bunyi bahasa dan vokal yang wujud dalam kajian ini. Kaedah kualitatif lebih memberi perhatian kepada temu bual yang mendalam bagi memastikan supaya maklumat diperolehi secara langsung mengenai dunia sosial. Terdapat beberapa kaedah yang digunakan dalam kajian ini, antaranya ialah kaedah temu bual, senarai daftar kata Swadesh, pemilihan informan, dan pemilihan kawasan kajian. Menurut Wan Hashim Wan Teh (1980), temu bual ialah satu proses interaksi antara penemu bual dengan informan yang bertujuan mendapatkan maklumat (dipetik dalam Norfazila Ab.Hamid \& Rahim Aman, 2016).

Temu bual bersama dua orang informan yang terdiri daripada masyarakat Melanau di Kampung Belawai dan merupakan penutur jati dialek Melanau Rajang. Sesi temu bual ini dijalankan dengan menggunakan alat rakaman untuk merakamkan sebutan perkataan dalam dialek Melanau Rajang di kawasan Belawai. Senarai kata yang disediakan adalah berdasarkan kepada 250 daftar kata Swadesh (Samarin, 1967). Senarai daftar kata Swadesh digunakan semasa sesi menemu bual informan dan informan telah menyebut daftar kata tersebut dalam dialek Melanau Rajang di kawasan Belawai.

Dalam kajian ini, pemilihan informan dilakukan dengan terperinci berdasarkan kriteria pemilihan informan menurut Asmah Haji Omar (2001:48), iaitu dengan syarat bahawa keadaan organ pertuturan iaitu organ artikulasi informan masih dalam keadaan baik dan jelas pertuturannya. Seterusnya, informan tersebut haruslah memiliki kesihatan tubuh badan yang baik dan akhir sekali ialah penguasaan bahasa dari segi keaslian bahasanya atau dialek yang dituturkan haruslah tidak mengalami sebarang gangguan daripada bahasa atau dialek lain. Informan yang dipilih terdiri daripada dua orang informan iaitu seorang perempuan yang berumur 47 tahun dan seorang lelaki berumur 50 tahun.

Seterusnya, kawasan kajian yang dipilih dalam kajian ini ialah di Kampung Belawai Sarawak yang terdapat di daerah pentadbiran Tanjung Manis dalam Bahagian Mukah, Sarawak. Berdasarkan maklumat yang pengkaji dapat tentang Daerah Kecil Belawai ialah keluasan bagi Daerah Kecil Belawai ialah 730.53 km. Selain itu, Daerah Kecil Belawai diletakkan bawah pentadbiran Daerah Daro dalam Bahagian Mukah, Sarawak pada $1 \mathrm{Mac}$ 2002 dan akhirnya pada 1 Oktober 2015, Daerah Kecil Belawai telah dinaik taraf menjadi daerah penuh yang dinamakan sebagai Daerah Tanjung Manis (Portal Rasmi Pentadbiran Bahagian Mukah).

Kajian yang dijalankan ini adalah berlandaskan kepada pendekatan struktural yang telah dipelopori oleh Ferdinand de Saussure (1960). Teori ini merupakan pendekatan yang berasaskan kepada prinsip-prinsip teori 
struturalisme (Norfazila Ab. Hamid, 2016). Pemilihan pendekatan struktural ini diguna pakai didasarkan kepada beberapa hipotesis umum yang terdapat dalam pendekatan ini. Antaranya ialah, kaedah yang dipakai dalam pendekatan ini bersifat empiris iaitu dikenali sebagai induktif. Kedua ialah bahasa adalah ujaran dan kemudian diikuti dengan tulisan yang bermaksud bahasa lisan yang akan diteliti dan dicatat. Ketiga pula, bahasa merupakan satu produk yang terdiri daripada unsur bunyi dan makna dan akhir sekali ialah pengelasan bunyi adalah berdasarkan distribusinya (Norfazila Ab. Hamid, 2016). Pendekatan struktural ini dapat dilihat sangat sesuai digunakan dalam kajian yang dijalankan berdasarkan objektif kajian yang dikemukakan. Dalam kajian ini, data yang diperoleh akn ditranskripsi terlebih dahulu ke dalam bentuk fonetik dan fonemik. Transkripsi ini digunakan bagi menunjukkan ciri-ciri bunyi yang terdapat dalam perkataan yang dituturkan oleh informan supaya ujaran bagiu setiap perkataan yang ditranskripsi tersebut disebut dengan bunyi yang tepat.

\section{DAPATAN KAJIAN}

Dalam bahagian ini, pengkaji memaparkan inventori fonem vokal yang wujud dalam dialek Melanau Rajang di kawasan Belawai. Selain itu juga, kedudukan kewujudan bagi setiap fonem vokal turut dikenal pasti untuk memperlihatkan sama ada fonem tersebut hadir pada awal, tengah, akhir ataupun hadir pada setiap posisi. Analisis dapatan yang dijalankan adalah berdasarkan kepada data yang diperolehi semasa sesi temu bual bersama informan dan berpandukan kepada 250 senarai daftar kata Swadesh yang digunakan.

\section{Inventori Fonem Vokal}

Dalam buku Asas Fonetik ada menjelaskan bahawa bunyi-bunyi vokal melibatkan udara agresif sahaja iaitu udara yang dihembus keluar semasa menghasilkan bunyi (Nor Hashimah Jalaluddin, 2007). Bahagian yang terlibat dalam penghasilan bunyi-bunyi vokal ini ialah kedudukan lidah sama ada tinggi, separuh tinggi, separuh rendah dan rendah. Keadaan bibir turut memainkan peranan semasa menghasilkan bunyi-bunyi vokal yang wujud dalam sesutau bahasa. Bibir akan menjadi bundar apabila menghasilkan bunyi-bunyi vokal belakang sementara bibir akan menjadi hampar apabila menghasilkan bunyi-bunyi vokal depan (Nor Hashimah Jalaluddin, 2007). Jones (1956) menyatakan bahawa vokal ialah bunyi-bunyi bersuara yang ketika menghasilkannya udara keluar terus-menerus dari paru-paru menerusi rongga mulut tanpa mengalami gangguan atau penyempitan yang boleh menimbulkan bunyi-bunyi geseran (dipetik dalam Salbia Hassan, 2016).

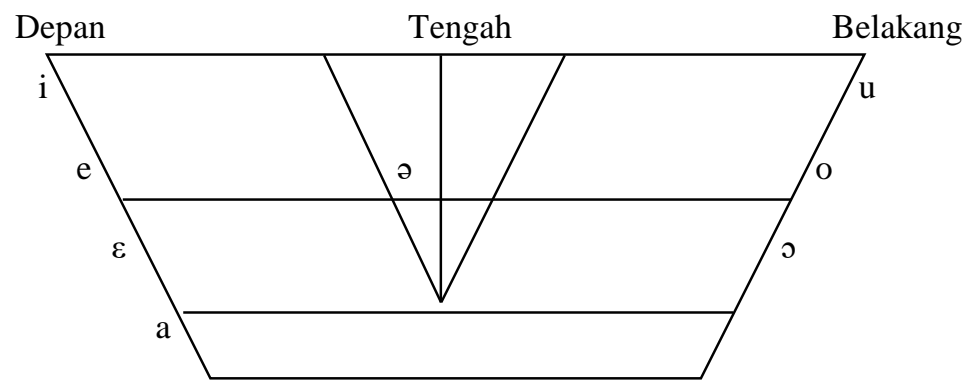

Gambar Rajah 1. Vokal Kardinal Dialek Melanau Belawai.

Persatuan Fonetik Antarabangsa telah mengeluarkan buku tentang prinsip-prinsip vokal kardinal yang terdiri daripada lapan vokal yang utama iaitu [i], [e], [ə], [a], [u], [o], [o], dan [a] (Raja Mukhtaruddin Raja Mohd. Dain, 1982). Dalam kajian ini, kedua-dua objektif yang telah ditetapkan telah dianalisis secara serentak. Berdasarkan kajian terhadap dialek Melanau Rajang di kawasan Belawai, pengkaji mendapati sistem vokal yang wujud dalam dialek ini terdiri daripada sistem lapan vokal kardinal yang merupakan perkembangan daripada sistem enam vokal. Perkembangan itu berupa pemecahan fonemik yang berlaku pada /e/ yang berpecah dua menjadi /e/ dan / $\varepsilon /$ dan /o/ berpecah menjadi /o/ dan /o/ (Asmah Haji Omar, 2008). Dalam kajian ini, kedua-dua objektif yang telah ditetapkan telah dianalisis secara serentak. Gambar Rajah 1 menunjukkan gambaran kedudukan bunyi-bunyi vokal kardinal dialek Melanau Rajang di kawasan Belawai iaitu lapan vokal kardinal yang terdiri daripada dua fonem vokal tinggi iaitu [i] dan [u], tiga fonem vokal separuh tinggi iaitu [e], [ə] dan $[0]$, serta dua fonem vokal separuh rendah $[\varepsilon]$ dan [0]. Fonem vokal yang akhir sekali ialah vokal rendah hadapan disebut sebagai vokal [a]. 


\section{Distribusi/aliterasi Fonem Vokal}

Bahagian ini menunjukkan distribusi bagi fonem vokal yang wujud dalam dialek Melanau Rajang di kawasan Belawai. Hasil daripada analisis data yang diperolehi menunjukkan bahawa tidak semua fonem vokal dalam dialek ini mempunyai beban tugas yang penuh. Hal ini demikian kerana, terdapat beberapa fonem vokal yang tidak hadir pada semua posisi kata sama ada awal, tengah ataupun akhir.

Jadual 1. Vokal Depan Sempit [i].

\begin{tabular}{|c|c|c|c|c|c|c|}
\hline \multirow[t]{2}{*}{ Vokal } & \multicolumn{2}{|c|}{ Awal } & \multicolumn{2}{|c|}{ Tengah } & \multicolumn{2}{|c|}{ Akhir } \\
\hline & Fonemik & Fonetik & Fonemik & Fonetik & Fonemik & Fonetik \\
\hline \multirow{5}{*}{ [i] } & /ins/ & [inõ] & /dziak/ & [dzijak] & /bəyəsi/ & [bәуәsi] \\
\hline & /ikoy/ & [ikoy] & /dzinaw/ & [dzinãw] & /amaw kusi/ & [amãw kusi] \\
\hline & /ikan/ & [ikan] & /kəlitah/ & [kəlitah] & /kami/ & [kamĩ] \\
\hline & /isay/ & [isay] & /nip/ & [nĩp’] & - & - \\
\hline & /idun/ & [idun] & /kitel/ & [kitel] & - & - \\
\hline
\end{tabular}

Berdasarkan Jadual 1, dapat dibuktikan bahawa fonem vokal depan sempit [i] dialek Melanau Rajang di kawasan Belawai mempunyai beban tugas yang penuh kerana hadir di semua posisi kata. Berdasarkan 250 daftar Swadesh yang digunakan, dapat dilihat bahawa fonem vokal depan sempit di posisi akhir kata lebih sedikit penggunaannya berbanding posisi awal dan tengah. Maksud perkataan [ikoy] dalam posisi awal ialah 'ekor' manakala perkataan [ḋinãw] dalam posisi tengah kata membawa maksud 'berapa'. Perkataan di posisi akhir kata iaitu [bəyəsi] membawa maksud 'bersih'.

Jadual 2. Vokal Depan Separuh Sempit [e].

\begin{tabular}{ccccccc}
\hline \multirow{2}{*}{ Vokal } & \multicolumn{2}{c}{ Awal } & \multicolumn{2}{c}{ Tengah } & \multicolumn{2}{c}{ Akhir } \\
\cline { 2 - 6 } & Fonemik & Fonetik & Fonemik & Fonetik & Fonemik & Fonetik \\
\hline & - & - & $/$ mey yah/ & {$[$ mẽy yãh] } & - & - \\
{$[\mathrm{e}]$} & - & - & $/$ madem/ & {$[$ mãdem] } & - & - \\
& - & - & $/$ gite?/ & {$[$ gite?] } & - & - \\
& - & - & $/$ gej/ & {$[$ gen] } & - & - \\
\hline
\end{tabular}

Berdasarkan Jadual 2, dapat dilihat bahawa vokal depan separuh sempit [e] turut wujud dalam dialek Melanau Rajang kawasan Belawai berdasarkan daftar kata Swadesh yang digunakan. Perkara ini menunjukkan bahawa fonem vokal depan separuh sempit [e] tidak mempunyai beban tugas yang penuh kerana tidak memenuhi posisi awal dan akhir kata. Maksud perkataan [gen] dalam posisi tengah kata di atas membawa maksud 'kawan'. Berdasarkan penganalisisan data, didapati kewujudan vokal [e] pada awal kata tidak dijumpai dalam senarai 250 daftar kata Swadesh yang digunakan hasil daripada temu bual bersama informan. Bagi akhir kata pula, vokal [e] turut tidak wujud kerana kebanyakan perkataan yang berakhir dengan bunyi vokal [e] akan mengalami geluncuran ataupun berubah menjadi diftong [ey]. Bagi pengkaji, memandangkan kajian ini hanya dihadkan kepada 250 daftar kata Swadesh, maka hasil dapatan yang dipaparkan dalam tinjauan awal ini telah menunjukkan bahawa kehadiran vokal [e] dalam dialek Melanau Rajang di kawasan Belawai tidak wujud pada awal dan akhir kata. 
Jadual 3: Vokal Depan Luas [a].

\begin{tabular}{|c|c|c|c|c|c|c|}
\hline \multirow[t]{2}{*}{ Vokal } & \multicolumn{2}{|c|}{ Awal } & \multicolumn{2}{|c|}{ Tengah } & \multicolumn{2}{|c|}{ Akhir } \\
\hline & Fonemik & Fonetik & Fonemik & Fonetik & Fonemik & Fonetik \\
\hline \multirow{5}{*}{ [a] } & /abo/ & [abo] & /likaw/ & [likaw] & /kala/ & [kala] \\
\hline & /adek/ & [adek] & /siaw/ & [sijaw] & - & - \\
\hline & /aso/ & [aso] & /may/ & [mãy] & - & - \\
\hline & /apuy/ & [apuy] & /saw/ & [saw] & - & - \\
\hline & /anus/ & [anũs] & /kəlakəy/ & [kəlakəy] & - & - \\
\hline
\end{tabular}

Jadual 3 menunjukkan bahawa vokal depan luas banyak digunakan pada setiap posisi kata dalam dialek Melanau Rajang di kawasan Belawai. Contoh posisi awal kata ialah perkataan [anũs] yang bermaksud 'asap' manakala perkataan di posisi tengah pula ialah [sijaw] yang membawa maksud 'ayam'. Untuk bahagian akhir kata, hanya satu sahaja contoh vokal depan luas [a] yang wujud berdasarkan daftar kata Swadesh yang digunakan iaitu [kala] yang bermaksud 'kuala'. Rajah di atas juga menunjukkan bahawa vokal depan luas [a] dalam dialek ini mempunyi beban tugas yang penuh kerana hadir di setiap posisi iaitu di awal, tengah dan akhir kata.

Jadual 4. Vokal Depan Separuh Luas $[\varepsilon]$.

\begin{tabular}{|c|c|c|c|c|c|c|}
\hline \multirow[t]{2}{*}{ Vokal } & \multicolumn{2}{|l|}{ Awal } & \multicolumn{2}{|l|}{ Tengah } & \multicolumn{2}{|l|}{ Akhir } \\
\hline & Fonemik & Fonetik & Fonemik & Fonetik & Fonemik & Fonetik \\
\hline & - & - & /ume?/ & [umẽ?] & /məle/ & [mãle] \\
\hline$[\varepsilon]$ & - & - & /kamek/ & [kamẽk] & - & - \\
\hline
\end{tabular}

Jadual 4 menunjukkan bahawa daftar kata Swadesh yang digunakan oleh pengkaji tidak menjumpai banyak penggunaan vokal depan separuh luas $[\varepsilon]$ dalam dialek Melanau Rajang di kawasan Belawai. Selain itu, kewujudan vokal ini dalam dialek yang dipilih tidak mempunyai beban tugas yang penuh kerana vokal depan

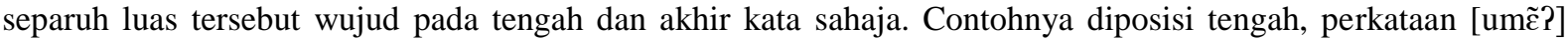
bermaksud 'kecil' manakala pada akhir kata pula [mõlø] membawa maksud 'membeli'.

Jadual 5. Vokal Tengah [ə].

\begin{tabular}{|c|c|c|c|c|c|c|}
\hline \multirow[t]{2}{*}{ Vokal } & \multicolumn{2}{|c|}{ Awal } & \multicolumn{2}{|c|}{ Tengah } & \multicolumn{2}{|c|}{ Akhir } \\
\hline & Fonemik & Fonetik & Fonemik & Fonetik & Fonemik & Fonetik \\
\hline \multirow{5}{*}{ [ə] } & - & - & /nəyəban/ & [nว̃yəban] & - & - \\
\hline & - & - & /bota?/ & [bəta?] & - & - \\
\hline & - & - & /dzolak/ & [dzəlak] & - & - \\
\hline & - & - & /biləm/ & [biləm] & - & - \\
\hline & - & - & /kəlah/ & [kəlah] & - & - \\
\hline
\end{tabular}

Vokal tengah [ə] banyak digunakan pada tengah kata dalam dialek Melanau Belawai seperti yag dinyatakan dalam Jadual 5. Berdasarkan daftar Swadesh yang digunakan oleh pengkaji mendapati bahawa tidak ada satu pun perkataan yang mempunyai vokal tengah pada awal dan akhir kata. Contoh perkataan dalam posisi tengah ialah [biləm] yang mempunyai maksud 'hitam'. Dapat dibuktikan bahawa vokal tengah dalam dialek ini tidak mempunyai beban tugas yang penuh kerana tidak memenuhi setiap posisi kata. 
Jadual 6. Vokal Belakang Sempit [u].

\begin{tabular}{|c|c|c|c|c|c|c|}
\hline \multirow[t]{2}{*}{ Vokal } & \multicolumn{2}{|c|}{ Awal } & \multicolumn{2}{|c|}{ Tengah } & \multicolumn{2}{|c|}{ Akhir } \\
\hline & Fonemik & Fonetik & Fonemik & Fonetik & Fonemik & Fonetik \\
\hline \multirow{5}{*}[\mathrm{u}]{} & /udut/ & [udut'] & /muay/ & [mũ $\left.\tilde{u}^{w} \tilde{y}\right]$ & /dəbu/ & [dəbu] \\
\hline & /uduoy/ & [udu ${ }^{\mathrm{w}}$ on] & /butah/ & [butah] & - & - \\
\hline & /udzan/ & [udzan] & /bənupay/ & [bənũpay] & - & - \\
\hline & /ume?/ & [umẽ?] & /bukit/ & [bukit'] & - & - \\
\hline & /ukap/ & [ukap’] & /tus/ & [tus] & - & - \\
\hline
\end{tabular}

Contoh perkataan dalam Jadual 6 di atas menunjukkan bahawa vokal belakang sempit [u] ini mempunyai beban tugas yang penuh kerana vokal ini hadir pada setiap posisi kata. Namun begitu, didapati hanya satu perkataan yang wujud pada akhir kata tetapi hasil dapatan ini hanya berdasarkan kepada 250 daftar kata Swadesh yang digunakan dalam kajian ini. Contoh perkataan yang mempunyai vokal ini ialah [udut'], [tus] dan [dəbu] yang masing-masing membawa maksud 'daki', 'jarum' dan 'debu'.

Jadual 7. Vokal Belakang Separuh Sempit [o].

\begin{tabular}{|c|c|c|c|c|c|c|}
\hline \multirow[t]{2}{*}{ Vokal } & \multicolumn{2}{|c|}{ Awal } & \multicolumn{2}{|c|}{ Tengah } & \multicolumn{2}{|c|}{ Akhir } \\
\hline & Fonemik & Fonetik & Fonemik & Fonetik & Fonemik & Fonetik \\
\hline \multirow{5}{*}{ [o] } & - & - & /bakol/ & [bakol] & /tyilo/ & [tilo] \\
\hline & - & - & /bilo?/ & [bilo?] & - & - \\
\hline & - & - & /gadoy/ & [gadon] & - & - \\
\hline & - & - & /dzatoy/ & [dzaton] & - & - \\
\hline & - & - & /datok/ & [datok] & - & - \\
\hline
\end{tabular}

Jadual 7 menunjukkan bahawa vokal belakang separuh sempit [o] tururt wujud dalam dialek Melanau Rajang di kawasan Belawai. Perkataan-perkataan bagi contoh posisi tengah dan akhir kata dalam jadual 8 di atas mempunyai maksudnya yang tersendiri. Contohnya, perkataan [gadon] membawa maksud warna 'hijau' manakala perkataan [filo] pula bermaksud 'kuku'. Dapat diihat dalam rajah di atas bahawa vokal ini tidak mempunyai beban tugas yang penuh kerana tidak hadir pada awal kata.

Jadual 8. Vokal Belakang Separuh Luas [0].

\begin{tabular}{|c|c|c|c|c|c|c|}
\hline \multirow[t]{2}{*}{ Vokal } & \multicolumn{2}{|c|}{ Awal } & \multicolumn{2}{|c|}{ Tengah } & \multicolumn{2}{|c|}{ Akhir } \\
\hline & Fonemik & Fonetik & Fonemik & Fonetik & Fonemik & Fonetik \\
\hline \multirow{4}{*}[0]{} & - & - & /mubon/ & [mũbon] & /aso/ & [aso] \\
\hline & - & - & /mano?/ & [mãnõ?] & /bulo/ & [bulo] \\
\hline & - & - & /sədzo?/ & [sədzo?] & /kajo/ & [kajo] \\
\hline & - & - & /guso?/ & [guso?] & /ulo/ & [ulo] \\
\hline
\end{tabular}

Jadual 8 menunjukkan bahawa vokal belakang separuh luas [0] tidak mempunyai beban tugas yang penuh kerana tidak terdapat dalam posisi awal kata. Berdasarkan data yang diperoleh menunjukkan bahawa vokal ini hanya hadir pada tengah dan akhir kata sahaja dalam dialek Melanau Belawai. Hal ini demikian kerana, adapun fonem vokal belakang yang wujud pada awal kata ialah fonem [u] dan [o] sahaja. Maksud perkataan bagi salah satu contoh dalam rajah di atas ialah [mãnõ?] yang merujuk kepada 'burung' dan [ulo] yang membawa maksud 'kepala'. 


\section{PERBINCANGAN}

Hasil dapatan kajian ini sangat berbeza dengan kajian yang lepas dari segi jenis fonem vokal yang wujud dalam dialek Melanau yang dianalisis. Kajian lepas yang digunakan oleh pengkaji untuk membuat perbandingan merupakan kajian Rahim Aman, Norfazila Ab. Hamid \& Shahidi Abdul Hamid (2015) iaitu Rekonstruksi Vokal dan Diftong Bahasa Melanau Purba, kajian Norfazila Ab. Hamid (2016) bertajuk Kajian Awal Inventori Fonem Vokal \& Diftong Varian Melanau Oya dan kajian Norfazila Ab.Hamid \& Rahim Aman (2016) yang bertajuk Varian Melanau Sarawak: Tinjauan di Melanau Mukah.

Jumlah fonem yang wujud dalam dialek Melanau Rajang di kawasan Belawai berbeza dengan dialek Melanau di kawasan yang lain walaupun merupakan satu rumpun yang sama iaitu Melanau. Perkara ini dapat dilihat dalam kajian Norfazila Ab. Hamid (2016) yang menjelaskan bahawa terdapat enam vokal yang wujud dalam varian Melanau Oya iaitu [i, e, u, o, ə, a]. Kajian Norfazila Ab. Hamid \& Rahim Aman (2016) juga menunjukkan varian Melanau Mukah mempunyai enam fonem vokal yang sama dengan varian Melanau Oya. Manakala bagi kajian Rahim Aman, Norfazila Ab. Hamid \& Shahidi Abdul Hamid (2015) pula menunjukkan terdapat lima jenis fonem vokal dalam Bahasa Melanau Purba iaitu [i, u, o, ə, a]. Selain itu, dapat dikenal pasti bahawa terdapat beberapa fonem vokal yang tidak mempunyai beban tugas yang penuh iaitu vokal $[0,0, \varepsilon, \partial$, e], namun ada juga fonem vokal yang aktif atau dikatakan hadir pada setiap posisi kata seperti vokal [a, i, u].

Di samping itu, terdapat aspek lain yang dapat membezakan ketiga-tiga kajian lepas ini selain hasil dapatan yang ditunjukkan. Antaranya ialah instrumen kajian yang digunakan. Dalam kajian ini, pengkaji telah menggunakan 250 daftar kata Swadesh untuk menganalisis setiap fonem vokal, konsonan dan diftong yang wujud dalam dialek Melanau Rajang di kawasan Belawai. Manakala kajian Norfazila Ab.Hamid \& Rahim Aman (2016) dan kajian Norfazila Ab. Hamid (2016) telah menggunakan senarai kata sebanyak 473 perkataan yang terdiri daripada 12 domain makna seperti tubuh badan, kata kerja, alat rumah, nama dan ganti nama, binatang, persaudaraan, alat pertanian, makanan, waktu dan cuaca, kata ukuran, pakaian dan kata bilangan. Kajian Rahim Aman, Norfazila Ab. Hamid \& Shahidi Abdul Hamid (2015) pula menggunakan hasil daripada rekonstruksi fonem yang telah dilakukan terhadap tiga belas VM yang meliputi lokasi geografi setempat yang berbeza iaitu Mukah (MKH), Matu (MT), Dalat (DLT), Igan (IGN), Oya (OA), Balingian (BLGN), Daro (DO), Bintulu (BT), Medong (MDG), Sungai Ud (SG UD), Rajang (RJG), Kanowit (KNWT), dan Tanjong (TJG).

\section{KESIMPULAN}

Berdasarkan analisis yang dilakukan terhadap kajian ini, pengkaji mendapati bahawa dialek Melanau Rajang di kawasan Belawai ini mempunyai inventori fonem vokal yang berbeza dengan dialek Melanau di kawasan yang lain. Dalam kajian ini, dapat dirumuskan bahawa dialek Melanau Rajang di kawasan Belawai mempunyai 8 jenis fonem vokal iaitu [i, e, $\varepsilon, \mathrm{a}$, , , u, o, o]. Selain itu, objektif kedua ialah tentang distribusi fonem menunjukkan bahawa tidak semua fonem vokal dialek Melanau Rajang di kawasan Belawai menjalankan beban tugas yang penuh.

Hal ini demkian kerana, terdapat juga fonem vokal tidak hadir pada setiap posisi kata sama ada pada awal, tengah dan akhir kata. Kesemua bukti bagi kewujudan fonem-fonem ini adalah berdasarkan kepada 250 daftar kata Swadesh yang telah digunakan oleh pengkaji semasa menjalankan kajian ini. Di samping itu, penggunaan pendekatan struktural sangat sesuai digunakan untuk menganalisis data yang telah diperoleh. Kaedah rakaman yang turut digunakan sangat berguna untuk pengkaji kerana dapat meneliti semula perkataan yang disebut oleh informan-informan dengan jelas dan betul.

Di samping itu, kajian yang dijalankan ini mampu menunjukkan kepada masyarakat bahawa setiap pecahan dialek yang wujud dalam apa-apa bahasa mempunyai perbezaan termasuklah bahasa Melanau. Perkara ini dapat dibuktikan apabila penutur Melanau dari kawasan yang lain sememangnya ada yang tidak dapat memahami dialek dari kawasan yang lain. Seterusnya, kajian ini juga dijalankan bagi membuka ruang kepada pengkaji yang akan datang supaya dapat meneruskan kajian ini dan memperluaskan lagi kajian tentang fonologi lebih-lebih bagi dialek Melanau yang lain kerana kajian seperti ini masih kurang dijalankan. Hasil penemuan ini di harap dapat memberikan satu penemuan yang dapat merungkai segala permasalahan yang timbul dalam kajian-kajian yang lepas. Kajian ini dijalankan bagi mengisi segala kelompangan yang berlaku dalam kajian fonologi bagi bahasa Melanau. Selain itu, diharap supaya kajian ini dapat dijadikan sebagai pangkalan data dialek Melanau Rajang kawasan Belawai untuk kajian yang seterusnya, khususnya dalam bidang linguistik yang lain. 


\section{PENGHARGAAN}

Makalah ini merupakan sebahagian daripada penulisan Projek Tahun Akhir (PTA) di Fakulti Bahasa dan Komunikasi, UNIMAS bawah bimbingan penyelia, Puan Dayang Sariah Binti Abang Suhai. Sekalung penghargaan diucapkan kepada informan-informan saya iaitu Encik Zaidi Bin Zaini dan Puan Roziah Binti Bederas dari Kampung Tepi Laut Belawai yang telah memberikan kerjasama yang sangat baik kepada saya sepanjang kajian ini.

\section{RUJUKAN}

Asmah Haji Omar. (2001). Kaedah penyelidikan bahasa di lapangan. Kuala Lumpur, Malaysia. Dewan Bahasa dan Pustaka.

Asmah Haji Omar. (2008). Kaedah penyelidikan bahasa di lapangan. (Edisi ke-2). Kuala Lumpur, Malaysia: Dewan Bahasa dan Pustaka.

Noor Azureen Hamid, Sharifah Raihan Syed Jaafar, \& Tajul Aripin Kassin. (2016). Sistem fonologi dialek Melayu Saribas berasaskan fonologi generatif. Jurnal Bahasa, 16(1), 1-29.

Nor Hashimah Jalaluddin. (2007). Asas Fonetik. Kuala Lumpur, Malaysia. Dewan Bahasa dan Pustaka.

Norfazila Ab. Hamid. (2016). Kajian awal inventori fonem vokaldan diftong varian Melanau Oya. E-Proceeding International Conference on Posstgraduate Reasearch 2016 (ICPR2016), pp 300-308.

Norfazila Ab. Hamid, \& Rahim Aman. (2016). Varian Melanau Sarawak: Tinjauan di Melanau Mukah. Jurnal Melayu, 15(1), 99-112.

Rahim Aman, Norfazila Ab. Hamid, \& Shahidi Abdul Hamid. (2015). Rekonstruksi vokal dan diftong Bahasa Melanau purba. GEMA Online® Journal of Language Studies, 15(1), 189-206.

Raja Mukhtaruddin Raja Mohd. Dain. (1982). Ilmu Fonetik dan Linguistik. Petaling Jaya, Malaysia: Agensi Penerbitan Nusantara.

Salbia Hassan. (2016). Kajian fonologi dialek Melayu Kabong (Unpublished doctoral dissertation), University of Malaya, Kuala Lumpur, Malaysia.

Samarin, W.J. (1967). Field Linguistics: A guide to Linguistics field work. New York, NY: Holt, Rinehart, \& Winston.

Tengku Intan Zarina Tengku Puji, Mazlan Ibrahim, Zaimuariffudin Shukri Nordin, Ibtisam Abdullah, Nozira Salleh, Munirah Abd Ghani. (2014). Kepercayaan etnik Melanau dari sudut pandang Islam: Suatu analisa. E-proceeding of the $2^{\text {nd }}$ World Conference on Integration of Knowledge 2014 (WCIK 2014), pp 141-147.

Yasir Abd Rahman. (1987). Melanau Mukah (Satu Kajian Budaya). Kuala Lumpur, Malaysia: Dewan Bahasa dan Pustaka. 